\title{
Chemistry in solution: recent techniques and applications using soft X-ray spectroscopy
}

\author{
Kathrin M. Lange, ${ }^{a b}$ Alexander Kothe ${ }^{a b}$ and Emad F. Aziz ${ }^{* a b}$ \\ Received 16th December 2011, Accepted 18th January 2012 \\ DOI: $10.1039 / \mathrm{c} 2 \mathrm{cp} 24028 \mathrm{a}$
}

The aim of a more precise knowledge about molecular structures and the nature of chemical bonds is the driving force behind the development of numerous experimental methods and theories.

Recent soft X-ray based techniques provide novel opportunities for tackling the structure and the dynamics of chemical and biochemical systems in solution. In our research group we are developing experimental methods for mapping the electronic structure and dynamics of molecular systems in solution during bond-building and breaking using soft X-ray absorption and emission spectroscopy. The combination of such recent developments with conventional spectroscopy as well as theoretical modeling allows us to address open questions about hydrogen bonds, thermodynamics and active centers of biological systems. Based on the core-hole clock and pump-probe spectroscopy dynamics on the time scale from sub-femtoseconds up to picoseconds can be revealed.

\section{Introduction}

What is "the next step in the research for an understanding of the nature of life"? asks Linus Pauling at the end of his book "The nature of the chemical bond". ${ }^{1}$ According to his perspective, understanding the nature of chemical bonds allows understanding the nature of our life. The investigation of the nature of the chemical bond requires spectroscopic tools to probe the molecular orbitals (MOs) that are involved in the building and breaking of such bonds, as well as the electron dynamics through these bonds. Techniques to probe the evolution of such MOs on

${ }^{a}$ Helmholtz-Zentrum Berlin für Materialien und Energie, Albert-Einstein-Strasse 15, 12489 Berlin, Germany.

E-mail:emad.aziz@helmholtz-berlin.de

${ }^{b}$ Freie Universität Berlin, FB Physik, Arnimallee 14,

D-14195 Berlin, Germany the time scale of femtoseconds have been discussed in literatures. In a recent perspective by Wernet such techniques are addressed for systems in gas phase. ${ }^{2} \mathrm{X}$-Ray based techniques for watching ultrafast structure dynamics on the femtosecond time scale have been reviewed by Chergui and Zewail. ${ }^{3}$

Most chemical reactions and biological functions take place in the liquid phase. Accordingly, investigating the electronic structure of such systems under real conditions, in liquid, is of great relevance. Studies of MOs correlated to the K-edges of life elements or the L-edges of the $3 \mathrm{~d}$ transition metals pose a special challenge for liquid samples since they are located in the regime of soft X-rays which requires high vacuum condition. In this perspective article we present the recently developed techniques for the investigation of liquid samples using soft X-ray photon-in photon-out spectroscopy and highlight examples from various subject areas that became

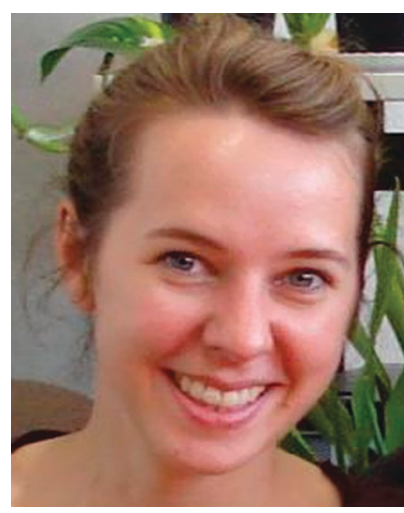

Kathrin M. Lange
Kathrin M. Lange is PhD student in the young investigator group Functional Materials in Solution at the HelmholtzZentrum Berlin. Goals of her thesis are the setting up of the high resolution $X E$ and $X A$ spectrometer LiXEdrom and the investigation of the electronic structure of liquids and dissolved functional materials.

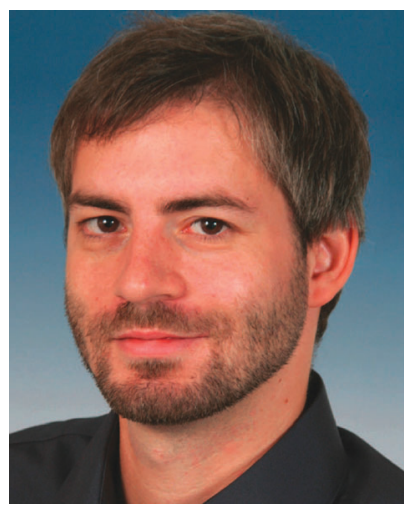

Alexander Kothe is PhD student in the young investigator group Functional Materials in Solution at the HelmholtzZentrum Berlin. His focus is to establish a laser pump-soft $X$-ray probe setup for investigations of ultrafast dynamics in functional materials using the recycle liquid microjet technique. 
addressable by these approaches. We discuss recent absorption studies of dissolved functional materials and new perspectives for explaining thermodynamic behavior of solutions based on local electronic structure information. Furthermore, we demonstrate our recently developed high resolution X-ray emission spectrometer on a micro-jet and explain how it helps to reveal the nature of the hydrogen bonds in solution. Concerning dynamics on the picosecond timescale we present for the first time a pump-probe setup for using a femtosecond laser pump combined with soft X-rays obtained from a synchrotron facility on a recyclable micro-jet. We will explain the potential of this setup for paving the way for future studies taking advantage of femtosecond X-ray pulses obtained from recently developed free electron laser X-ray light sources (XFELs). We also present a mechanism recently proposed by us, called the dark-channel-fluorescence-yield (DCFY ${ }^{4,5}$ ). Taking advantage of the core-hole clock, this process allows estimating the time scale of a charge transfer process down to sub-femtoseconds. Although the exact course of action as well as the quantification of this mechanism is still a work in progress, it could lead the soft X-ray spectroscopy towards the induced attosecond charge transfer dynamics. Note that, soft X-ray techniques based on electron-out spectroscopy, e.g. photoelectron spectroscopy and resonant Auger, are not the subject of this perspective and had been reviewed and discussed elsewhere. ${ }^{6-8}$

\section{X-Ray absorption at the L-edge of a protein active center in solution}

Porphyrin based materials are involved in many technological applications of various fields such as chemistry, biology, medicine, and nanotechnology, e.g. for molecular electronics. ${ }^{9-14}$ Despite this large number of practical applications, there is still very little known about the electronic structure of porphyrins under realistic conditions, i.e. at room temperature, in solution, at ambient pressure, and in the presence of counter-ions. Even less is known about the evolution of the electronic states and the structural changes of the porphyrin

Prof. Dr. Emad F. Aziz is

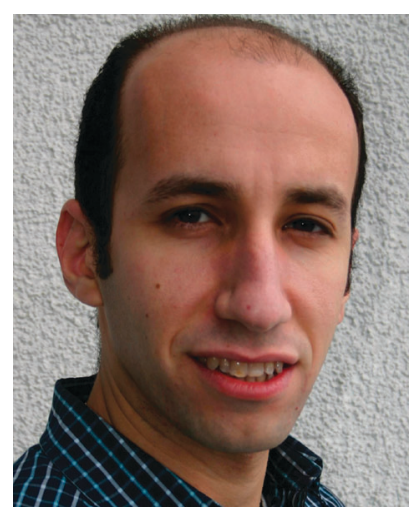

Emad F. Aziz professor of physics at the Freie Universität Berlin and head of the Structure and Dynamics of Functional Materials in Solution department at the HelmholtzZentrum Berlin. He is developing techniques to introduce ambient experimental conditions to soft X-ray light sources. His work was recognized with several prizes most recently, the Karl-Scheel Preis 2011 and an ERC Starting Grant 2011. For more information, see: http://www.helmholtz-berlin.de/forschung/funkma/ materialien-loesung/index_de.html,http://www.physik.fuberlin.de/ en/einrichtungen/ag/ag-aziz/index.html. systems upon photo-excitation under such conditions, despite two decades of research combining ultraviolet-visible (UV-Vis) pump with UV-Vis or hard X-ray probe techniques. ${ }^{15-21}$ One of our perspective goals is to investigate the light-induced dynamics in the molecular structure of porphyrins as found in biological systems as well as used in practical applications by means of time-resolved UV and soft X-ray spectroscopy. We will limit our discussion in this section to the metalloprotein active center as one example from the porphyrin family. A detailed discussion has been presented previously by us. ${ }^{22}$ Technically, the investigation of liquids using soft X-rays is challenging due to the large absorption cross section of air in this energy region. In order to separate the liquid from the vacuum in most of the recent soft X-ray absorption (XA) studies, the samples were contained in a cell consisting of soft $\mathrm{X}$-ray transparent thin (few hundreds of nm's) membrane windows made of carbon or silicon nitride $\left(\mathrm{Si}_{3} \mathrm{~N}_{4}\right)^{4,23-36}$ A further development of these sample holders allows the direct detection of the transmission signal with a semirefreshed sample. Liquid can flow in between two of these membranes in order to introduce the sample. ${ }^{37}$ Nagasaka et al. achieved moreover to introduce a fresh sample for every measuring point of their spectra. ${ }^{38}$ For measuring transmission XAS the flow is stopped. A schematic of such a transmission flow cell is presented in Fig. 1a. However, sample damage is a crucial point that has to be considered, especially for macromolecules like porphyrin related materials as their numerous strong and weak bonds can respond in a complex manner to the intense X-ray pulse. Flowing the liquid reduces the risk of sample damage with respect to static drop-behind-membrane cells. We employed such a flow-cell for XA measurements of the L-edge of the metal active center for investigating porphyrins in solution in the fluorescence yield (FY) mode as shown in Fig. $1 \mathrm{~b}$.

In the first reports on the L-edge XAS of proteins in solution, the active center of methemoglobin was investigated $^{39}$ and compared to catalase. ${ }^{29}$ The experimental spectra are shown in Fig. 1c and have been explained by means of multiplet simulations, showing the high spin nature of the iron active center. Although catalase and methemoglobin have very similar haem groups, which are both ferric, catalase decomposes hydrogen peroxide to water and oxygen very efficiently, while methemoglobin does not. We proposed that the origin of this is the $\pi$ back-donation of the Fe atom occurring in catalase, which confers on it a partial ferryl $\left(\mathrm{Fe}^{4+}\right)$ character; this is not the case in methemoglobin. The origin of the $\mathrm{Fe}^{4+}$ character could stem from the proximal tyrosine residue.

Hemocyanin has been investigated as well via the L-edge of the copper active center. ${ }^{40}$ Evidence was found that the oxygenation does not simply switch the copper valence state from $\mathrm{Cu}(\mathrm{I})$ to $\mathrm{Cu}$ (II), as was assumed classically. Water can replace the di-oxygen upon de-oxygenation by binding to the active site of the hemocyanin and withdrawing electrons from the $\mathrm{d}$ orbital of the copper.

Note that, all the L-edge XAS on the metal center of the protein were done using the flow cell technique. We assumed in these studies that the fast flow of the protein behind the membrane during the X-ray measurements avoids sample damage. Furthermore, we used UV-Vis spectroscopy as a 


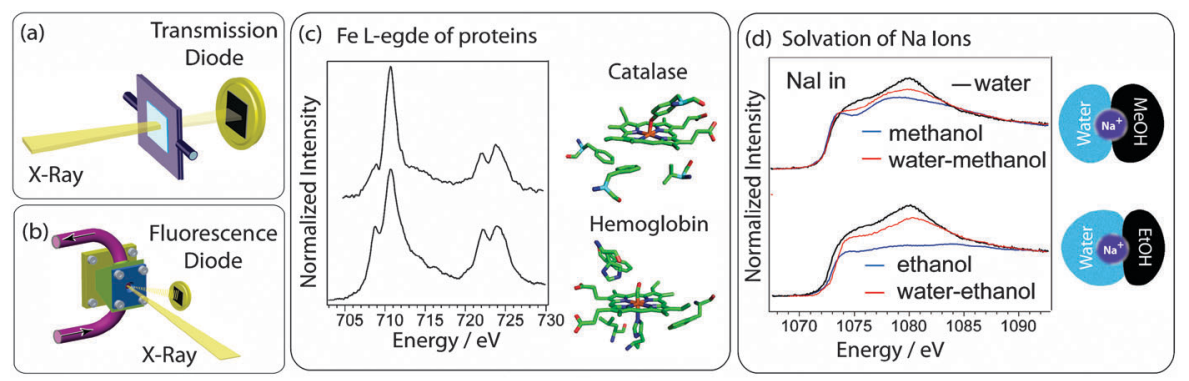

Fig. 1 (a) Schematic of a transmission cell for soft X-ray spectroscopy on liquids. (b) Schematic of a flowcell for detection in FY mode. (c) XA Fe L-edge spectra of the proteins catalase and hemoglobin in solution obtained from a flow-cell. (d) XA Na K-edge spectra of sodium ions in water-alcohol mixtures compared to the ones obtained in the pure solvent.

control method for our studies. Before and after introducing the protein to X-ray, a reference spectrum using the UV-Vis spectrometer was measured and compared. Although the later presented micro-jet technique would seem to be the ideal method to deliver proteins to X-ray without sample damage, this approach is still challenging since the samples can be exposed to high pressure during jet-operation. This could lead to a de-folding of the protein. We are currently planning a study to compare measurements of the active center from the micro-jet with the ones from a flow cell. Upon combination with UV-Vis and/or infra-red (IR) spectroscopy we hope to find the most appropriate way of introducing protein under real condition to any high vacuum spectroscopy.

\section{Thermodynamic behavior from electronic configuration}

In most cases the supply of a fresh sample is required to obtain reliable information of the electronic structure of a system. In our recent study of $\mathrm{NaI}$ in water/alcohol mixtures the challenge was not sample damage, but a chemical reaction induced by the soft X-ray photons in the presence of $\mathrm{I}^{-}$in the solution. Upon optimizing the flow speed accordingly and introducing a permanently fresh sample, we could obtain unaffected data, which allowed us to draw conclusions on the thermodynamic behavior of these systems. ${ }^{41}$ At first sight, obtaining thermodynamic information from local electronic structure information is not a straight forward process. Dixit et al. made the first attempts for explaining the special thermodynamic behavior of water-alcohol mixtures by their results obtained from neutron diffraction. ${ }^{42}$ Using XAS Guo et al. confirmed their results that the prevalence of water in the form of strings or clusters can explain the anomalous thermodynamics. ${ }^{43}$ We have used XAS to investigate a contradiction between theoretical predictions and experimental findings concerning the excess free energy of solvation $\left(\Delta G_{\text {exe }}\right)$ of $\mathrm{Na}^{+}$ions in water-alcohol mixtures. ${ }^{44}$ Experimentally the Gibbs energy of transfer $(\Delta G)$ can be determined via solubility, potentiometry or voltammetry measurements. It is not possible however to determine $\Delta G$ experimentally for a single ion, but only for electro-neutral combinations of ions. Only theoretical techniques can reveal the relevance of specific parameters governing the solvation process, such as polarizability or ion and solvent size. ${ }^{45-47}$ We used soft XAS at the Na K-edge to study the sodium halides solute in water and in low-order alcohols, such as methanol and ethanol, and in the corresponding two-component solvents, ${ }^{41}$ as presented in Fig. 1d. Analysis of the obtained spectra proposed that the solvation shell for the $\mathrm{Na}^{+}$ion in the water-methanol mixture is formed by three water and three methanol molecules. Analogously, for water and ethanol the spectra indicate that the first hydration shell of the $\mathrm{Na}^{+}$ion is composed predominantly of water and ethanol in a ratio of four water and two ethanol molecules. The same picture of a shared solvation shell can be drawn for the methanol-ethanol mixtures, consisting of four methanol and two ethanol molecules. We proposed that the structural differences of the shared solvation shell around $\mathrm{Na}^{+}$ions in the water-methanol mixture, compared to the water-ethanol mixture, provide a microscopic explanation for the different values of the excess free energy of solvation in these solvent systems. The respective $\Delta G$ values show that a transfer of $\mathrm{Na}^{+}$ to methanol is energetically favorable compared to a transfer to ethanol. For the binary mixtures with water however, a transfer to the ethanol containing mixture is advantageous. Our results presented above can now explain this behaviour. Whereas for the water-methanol mixture both solvents are equally involved in the formation of the solvation shell around the $\mathrm{Na}^{+}$, in the water-ethanol mixture, the ethanol contributes less to the solvation shell. In the latter case the $\mathrm{Na}^{+}$ions energetically prefer to be surrounded by a higher number of water molecules which leads to a lower energy of transfer.

As one key for the differing solvation shell structures of the ions in the different water-alcohol mixtures, hydrogen bond interactions are proposed, which are not yet considered in the discussed theoretical approaches. This finding emphasizes the importance of specific interactions in the solvation of ions in binary mixtures of water and less polar media, thus providing the experimental basis for an accurate understanding of these processes. These studies prepare the ground for introducing larger molecules in solution, e.g. amino-acids and proteins, as well as binary mixtures of solvents and for revealing their thermodynamic behaviors.

\section{X-Ray absorption and emission from a liquid micro-jet}

When using membranes in a drop-behind-membrane- or flow-cell, it has to be considered that elements that are contained in the membrane material ( $\mathrm{Si}$ and $\mathrm{N}$ ), or energetically follow them, are not directly measurable. Furthermore the membrane leads to a reduction of signal since no membrane is ideally transparent for any energy range in the 
soft X-ray regime. Measuring techniques which require a high incoming flux, e.g. X-ray emission spectroscopy (XES), suffer from the loss of photons leading to long data acquisition times. For very low concentrated samples, e.g. porphyrin based materials where typical concentrations are in the range of few millimolar, such a loss of intensity can be detrimental. ${ }^{29,39,40}$ Additionally interactions with the membrane, like hydrophobic or hydrophilic effects or chemical reactions, can induce artifacts in the spectra and vary them as a function of irradiation. ${ }^{48}$

In order to avoid these negative aspects correlated to membranes, a liquid micro-jet can be used to provide constantly a fresh sample. This technique was developed by Faubel and co-workers ${ }^{49}$ and was already successfully applied for spectroscopies based on electron detection. ${ }^{50-53}$ We recently developed the first high-resolution XES and fluorescence yield (FY) XAS setup in combination with the micro-jet technique (membraneless spectrometer). ${ }^{54,55}$ Proof of principle measurements were carried out on the oxygen $\mathrm{K}$-edge of liquid water and the nickel L-edge of $\mathrm{NiCl}_{2}$ aqueous solution under resonant and nonresonant excitation. A schematic picture of the setup is presented in Fig. 2a. The XA spectra were recorded in the total fluorescence yield (TFY) mode with a GaAsP diode. For the XE measurements a Gamma Data MCP-CCD-detector combined with a self-developed grating holder was used in Rowlandgeometry (see Fig. 2a). By rotation of the holder, it can be chosen between four different blazed gratings covering the energy range from $20 \mathrm{eV}$ up to $1200 \mathrm{eV}$. On the oxygen K-edge of liquid water we show that (Fig. 2b) our newly developed liquid-jet XES spectrometer achieves a resolution comparable to the recently published high resolution XES measurements carried out on membrane cells. ${ }^{56,57}$ In the top of Fig. $2 b$ the XA spectrum of $\mathrm{H}_{2} \mathrm{O}$ obtained from the micro-jet is presented, showing three characteristic spectral features: the pre-edge, the main-edge and the post-edge around 535, 537.5 and $540 \mathrm{eV}$, respectively. Note that because of saturation effects the pre- and post-edge features are overemphasized with respect to the mainedge feature. The XES mapping, beginning with the resonant excitation of the pre-edge at $534 \mathrm{eV}$ and proceeding upwards, is shown in the bottom part of Fig. 2b. Whereas XAS probes the unoccupied density of electronic states, XES reveals information about the occupied electronic states, which are the $1 b_{2}, 3 a_{1}$ and the $1 b_{1}$ for water. The apparent broadening of the spectral features of the binding $1 b_{2}$ and $3 a_{1}$ orbital in comparison to non-bonding lone-pair $1 b_{1}$ is due to core-hole-induced proton transfer dynamics. ${ }^{56,58}$ Upon increasing the excitation energy a splitting of the $1 b_{1}$ spectral feature into the two peaks $1 b_{1}^{\prime}$ and $1 b_{1}^{\prime \prime}$ is observed. The origin of this splitting has been discussed controversially before ${ }^{56-58}$ also in detail in our recent study of water/acetonitrile mixtures. ${ }^{55} \mathrm{We}$ have investigated in this study the influence of hydrogen bonds (HB) on XA and XE spectra of water by reducing its $\mathrm{HB}$ strength upon decreasing its concentration in the acetonitrile solvent. In the XE spectra the lowenergy component of the sharp double feature is reduced upon $\mathrm{HB}$ breaking, and its relative intensity can thus be used as a probe for H-bonding.

Currently, we are implementing a recycle recovery of the jet for the XE spectrometer as shown schematically in Fig. 2a. This allows us to control X-ray photon induced effects via in situ investigation using conventional spectroscopies. The recycle jet will be presented in detail later in this perspective.

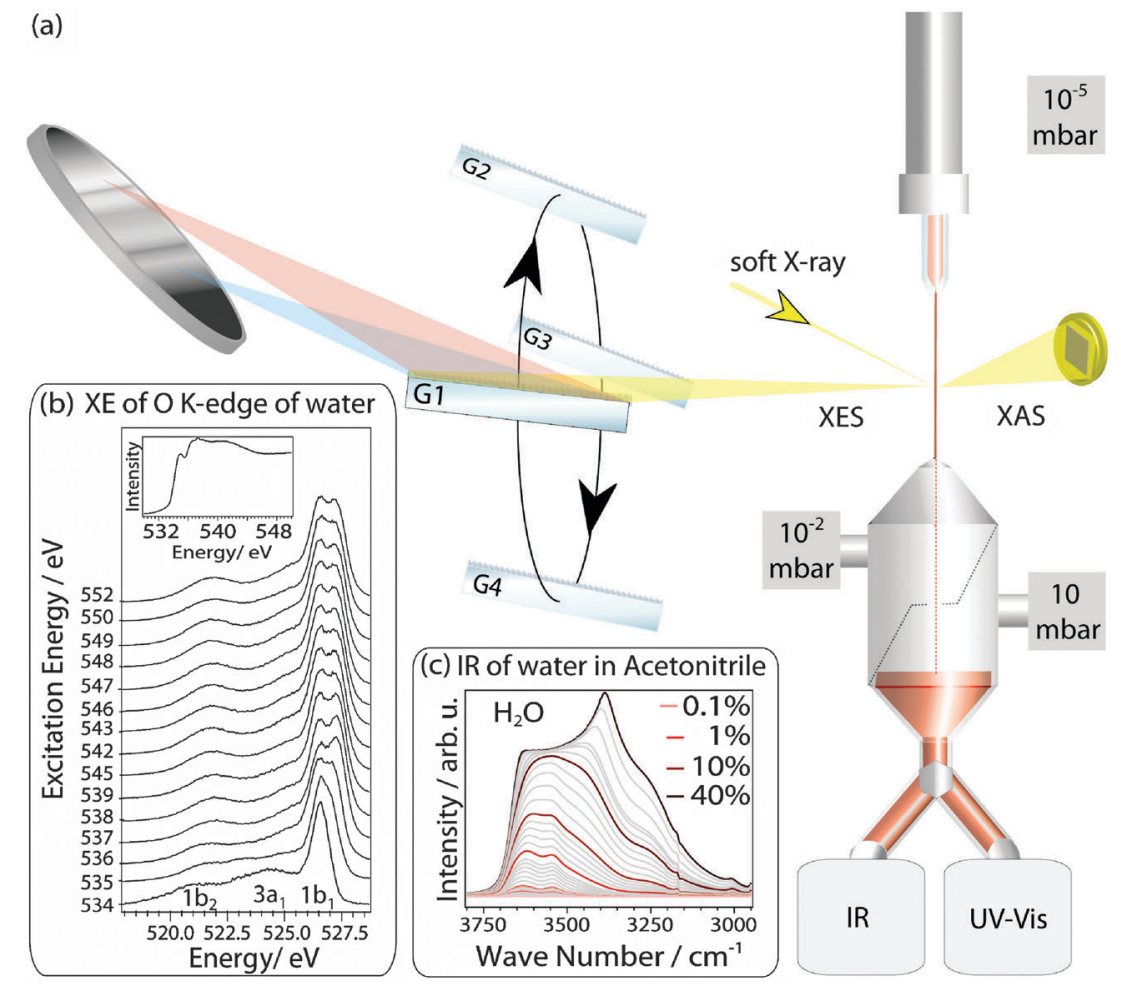

Fig. 2 (a) Schematic of the Rowland-circle based high resolution XE and XA spectrometer for measurements on a liquid micro-jet. (b) XE spectra of the oxygen K-edge of liquid water. The related absorption spectrum is shown in the inset. (c) FT-IR spectra of water-acetonitrile mixtures of various concentrations. 


\section{X-Ray absorption combined with infrared spectroscopy}

For reaching a more comprehensive understanding of the behavior of chemical bonds in solution, a combination of the well-established conventional spectroscopies with the $\mathrm{X}$-ray based techniques is recommended. In order to investigate the nature of $\mathrm{HB}$ in water-solvent-mixtures we recently began to combine Fourier transform infrared (FT-IR) spectroscopy with XAS. ${ }^{48}$ FT-IR reveals information about the vibrational structure of the investigated molecules and is therefore a sensitive tool for determining the binding partners of the water molecule as well as the symmetry of the binding. The distinct properties of the solvents in terms of polarity, hydrophobicity, and solubility for water allow a comprehensive investigation of the emerging water structures upon increasing water concentration. In the IR spectra (Fig. 2c), the onset of H-bonding among water molecules forming water clusters is indicated by the appearance of the respective bands around $3400 \mathrm{~cm}^{-1}$. Note that neat water shows a broad band around $3400 \mathrm{~cm}^{-1} .{ }^{59}$ For water in acetonitrile, upon raising concentration an equal increase of the anti-symmetric and the symmetric stretching bands intensity ${ }^{60}$ is observed, up to about $1 \%$ of solute water. A further increase of the water content leads to the rise of additional bands around $3400 \mathrm{~cm}^{-1}$. These bands indicate a clustering of water molecules within the solvent. In order to study the fingerprint of hydrogen bonding in the X-ray spectra (note that, the XA spectra in ref. 48 were strongly affected by the membrane as we have observed later upon repeating the measurement in our micro-jet setup presented in ref. 55), it was important to know, at which concentration water molecules are isolated in the acetonitrile and from which concentration water clustering sets in. We could obtain this information from the presented complementary FT-IR measurements. As a perspective we plan to implement in situ IR spectroscopy with the XE spectrometer as presented schematically in Fig. 2a to obtain the IR band of the probed bonds before and after X-ray irradiation.

\section{The recycle micro-jet: sample handling for long measuring times}

In order to study the electronic-structure dynamics of functional materials in solution the pump-probe method is one of the most suitable techniques. This technique requires measurement duration of several days to obtain a significant signal-tonoise ratio. It has been applied to probe the K-edges of transition metals which lie in the hard X-ray regime, ${ }^{17-19,61-66}$ where no high vacuum (HV) conditions are required due to the high photon energies of several $\mathrm{keV}$. In the soft X-ray regime, laser pump/XAS probe was recently demonstrated probing changes of the oxygen K-edge of liquid water upon infrared laser pump ${ }^{67-69}$ as well as for probing the modifications in the electronic structure of $\left[\mathrm{Fe}\left(\operatorname{tren}(\mathrm{py})_{3}\right)\right]^{2+}$ dissolved in acetonitrile via the L-edge of iron. ${ }^{70,71}$ In these experiments the samples were prepared as a drop between two $\mathrm{Si}_{3} \mathrm{~N}_{4}$ membranes, and the X-ray absorption was measured in transmission mode. However, while this approach of introducing solution to $\mathrm{HV}$ conditions is working in the above mentioned cases, it would not be suitable for many biochemical systems. In such systems the required high-intensity X-ray and laser irradiation can cause sample damage due to photochemistry or heating.

Here we present for the first time the membrane-free recyclemicro-jet technique for the laser pump and soft XAS probe in the fluorescence yield (FY) mode for the investigation of molecular systems in solution. The liquid micro-jet technique is well established within the scope of X-ray photoelectron spectroscopy, ${ }^{53,72-76} \mathrm{XAS}^{77}$ and XES. ${ }^{48,54}$ For the latter work, we could maintain a pressure of $10^{-5}$ mbar in the chamber to perform XAS/XES measurements. Such low pressure is usually achieved by collecting the liquid sample in a cool trap, which requires frequent venting and opening of the chamber in order to empty and clean the trap. For laser pump/X-ray probe experiments which are highly sensitive to precise spatial alignment between the laser pulses, the X-ray pulses and the micro-jet, this procedure is not feasible. To overcome this challenge a recycle sample delivery system for the liquid jet is implemented as illustrated in Fig. 3a. An enlarged detail for the laminar part of the jet is presented in Fig. 3b. This novel installation permits the collection of the sample in liquid phase from the micro-jet and its recovery from the chamber without interrupting the measurements. Here, the installation was operated by pumping $120 \mathrm{ml}$ of filtered sample with an HPLC pump from a sample storage loop through a micro-jet nozzle of $25 \mu \mathrm{m}$ diameter. This nozzle is anchored to a holder mounted on a $3 \mathrm{D}$ motorized stage. A stable liquid jet is created with a velocity of approximately $100 \mathrm{~m} \mathrm{~s}^{-1}$ and $5-10 \mathrm{~mm}$ region of laminar flow. The liquid jet travels 3 to $4 \mathrm{~mm}$ through the $\mathrm{HV}$ chamber before it enters the liquid trap through a $150 \mu \mathrm{m}$ pinhole of the temperaturecontrolled copper skimmer. ${ }^{78}$ This skimmer is only thermally coupled by isolating ceramics and a knife-edge to the liquid trap. This permits heating of the skimmer during alignment to avoid adhesion of the solvent on the pinhole. The pressure in the liquid-trap is, depending on the temperature, between 10 to 15 mbar for aqueous solutions. ${ }^{78}$ The trap is connected to the recovery outside of the chamber through a tube with a valve. To retrieve the sample, the recovery is pumped to a pressure of 1 mbar. After venting, the sample can be taken out and measured in an UV-Vis or IR spectrometer to compare with a fresh sample. If no radiation damage occurs, the sample can be loaded to the storage loop again for further measurements.

Fig. $3 \mathrm{c}$ shows the XA-FY spectrum of the oxygen K-edge of liquid water (saturated spectrum), obtained from the microjet, and in comparison with a gas phase spectrum obtained by shifting the jet $100 \mu \mathrm{m}$ from the focus of alignment. Both spectra are in good agreement with former results. ${ }^{54,55}$ Evidently, this result demonstrates the efficiency of our newly designed recycle liquid trap for maintaining good vacuum conditions and ensures measuring the liquid micro-jet with negligible gas phase background. Fig. $3 \mathrm{~d}$ shows the $\mathrm{L}_{3}$-edge XA spectrum of iron obtained from $800 \mathrm{mM} \mathrm{K}_{3}\left[\mathrm{Fe}(\mathrm{CN})_{6}\right]_{\mathrm{aq}}$. The spectrum shows a multiplet feature corresponding to the low-spin configuration, where the 5 electrons in the d-MOs are in the $t_{2 \mathrm{~g}}$ states built in an $\mathrm{O}_{\mathrm{h}}$ crystal field of $4.6 \mathrm{eV}$ with $6 \mathrm{CN}$ ligands around the $\mathrm{Fe}(\mathrm{III})$ center. The low spin configuration of this complex in its solid state has been shown. ${ }^{79,80}$ Interestingly, the complex in solution also prefers the low-spin configuration. Note that, the in situ optical absorption spectrum of this 

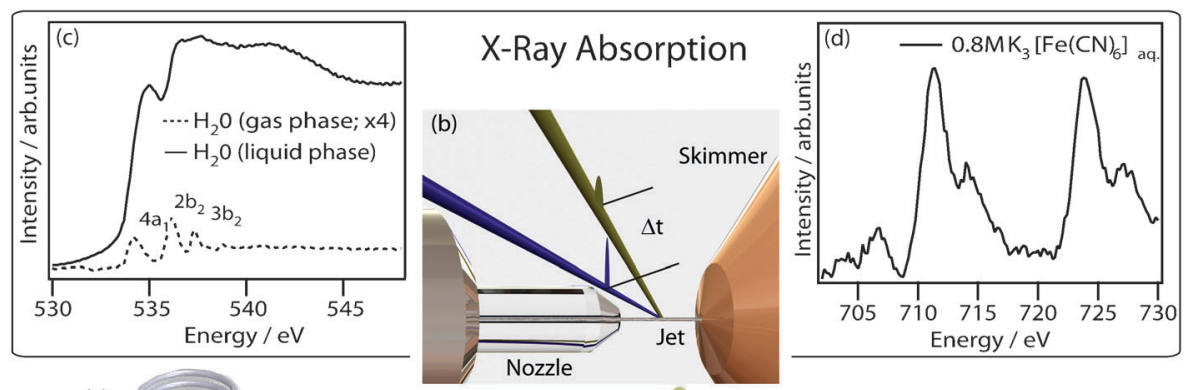

(a)
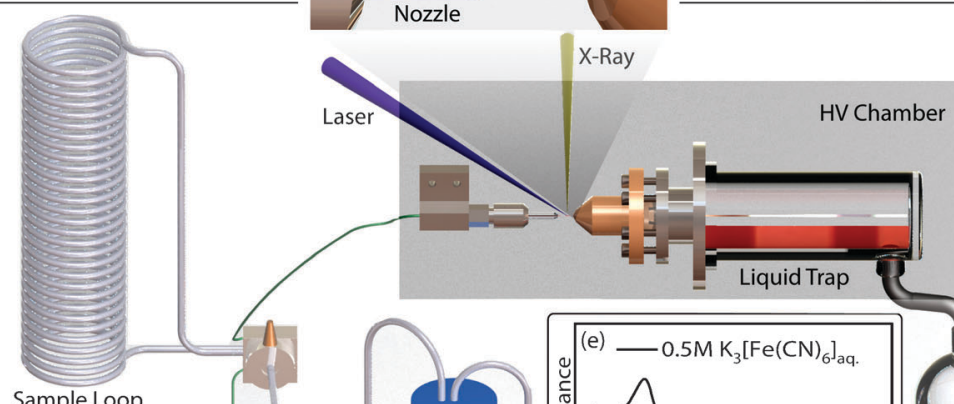

Sample Loop
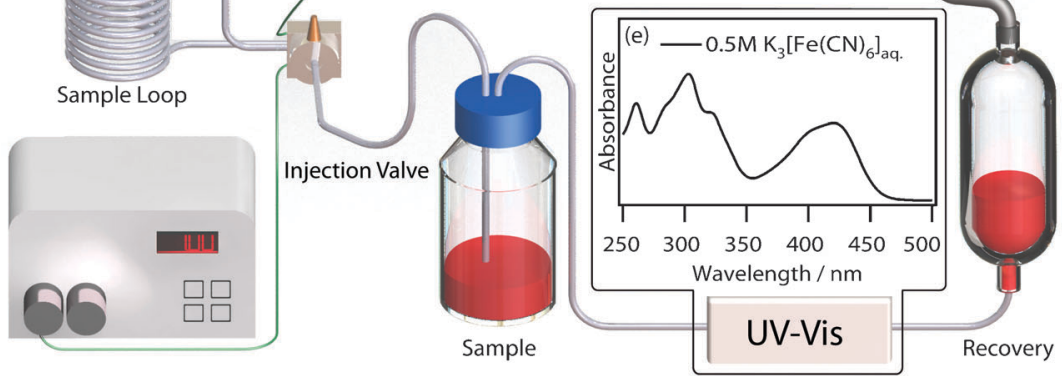

Fig. 3 (a) Schematic of the recycle micro-jet technique for pump-probe measurements. (b) Enlargement of the overlap area of micro-jet, X-ray and laser beam. (c) XA spectrum of the oxygen K-edge of gas phase water and liquid water. (d) XA spectrum of the iron $\mathrm{L}_{3}$-edge of $\mathrm{K}_{3}\left[\mathrm{Fe}(\mathrm{CN})_{6}\right]_{\mathrm{aq}}$. (e) UV-Vis spectrum of $\mathrm{K}_{3}\left[\mathrm{Fe}(\mathrm{CN})_{6}\right]_{\mathrm{aq}}$.

complex is shown in Fig. 3e. We are currently performing experiments on different complexes using a pump-probe scheme similar to the one presented in ref. 65. We are planning to investigate systems like the one which is previously done as a drop between membranes (e.g. $\left[\mathrm{Fe}\left(\operatorname{tren}(\mathrm{py})_{3}\right)\right]^{2+}$ dissolved in acetonitrile) to maintain a stable condition for the new setup. Accordingly, our perspective will be to investigate the molecular structure and the nature of chemical bonds of the active centers of proteins with different ligands $\left(\right.$ e.g. $\left.\mathrm{O}_{2}, \mathrm{CO}, \ldots\right)$. We would like to dissociate the ligand, and watch the recombination process to the metal center of the porphyrins via XAS.

\section{Ultrafast dynamics: dark-channel-fluorescence-yield (DCFY) spectroscopy}

A novel opportunity for characterizing ultrafast chargetransfer processes via the total fluorescence yield (TFY) L-edge XA spectra from transition metals (TM) has been reported recently by us. ${ }^{4,5}$ The FY spectra measured in solutions exhibit 'dips' below the fluorescence background. The proposed mechanism has been rationalized by the competition between the FY of the solute and surrounding species, and between the solute radiative channels (fluorescence) and non-radiative channels (in particular, charge transfer to the water molecules). It has been named dark-channel fluorescence yield (DCFY) and was employed to determine the nature, directionality and time-window of the radiation-induced charge transfer. Our observations indicate that the $\mathrm{L}_{3}$-edge features are affected more than the $\mathrm{L}_{2}$-edge features. The core-hole lifetime of the $\mathrm{L}_{2}$ edge $(\sim 0.7 \mathrm{fs})$ is shorter than that of the $\mathrm{L}_{3}$ edge $(\sim 2 \mathrm{fs}),{ }^{81}$ so it is likely that $\mathrm{L}_{2}$ is affected less by electron transfer because of its higher radiative decay rate. This also sets an upper limit for the induced electron transfer from the transition metal and the ligand. For example, in the case of $\mathrm{Fe}^{2+}$ in water, the induced electron transfer would be between 0.7 and 3 fs from the $\mathrm{Fe}^{2+}$ to the coordinated water molecules around. ${ }^{4}$

The XA measurements supporting the proposed DCFY mechanism were based on detection of the TFY. A crucial issue in obtaining XA spectra using the TFY approach is the distortion via different effects, e.g. saturation or self-absorption. ${ }^{82,83}$ Previously such effects were not considered in a quantitative manner. We are currently working on the clarification of two issues in order to facilitate the application of this method as a powerful tool in chemical sciences. Physically: how does the competition between the background and the emission from the probed elements contribute? Chemically: how informative can this process be with respect to strength and characteristics of chemical bonding? For this, we are combining the photo-electron spectroscopy with the resonant Auger spectroscopy and XES on different transition metal complexes in solution. Interestingly, we found that the resonant part of the dip observed in the TFY XA spectra is due to metal-to-water charge transfer. ${ }^{84}$ This is observed from the resonant enhancement of valence signal intensity arising from the interference of two identical final states created by a direct and Auger-electron emission. The most important conclusion from our valence-spectrum analysis is that 
metal $t_{2 \mathrm{~g}}$ levels of $\mathrm{Co}^{2+}$ overlap energetically and spatially well with the valence band of water, enabling strong orbital mixing in agreement with previous density-functional theory (DFT) calculations. $^{85}$

\section{Conclusion and perspective}

Liquid phase is an interesting environment for chemistry as it hosts many of the chemical processes in nature and in industrial applications. We have demonstrated in this perspective by various examples how an understanding of the nature of different chemical bonds (e.g. hydrogen, covalence, electrostatic) in liquid phase can be achieved by combining the recent soft $\mathrm{X}$-ray spectroscopic techniques using membrane-cells and micro-jets with conventional spectroscopy (e.g. FT-IR, UV-Vis, mass spectrometry). The newly developed recycle micro-jet is presented here as well for the first time with its perspective for pump-probe spectroscopy to observe the dynamics of biochemical functions under real conditions (room temperature and pressure). In our future research this setup will be used on the one hand for studying molecular dynamics in solution in tens of picoseconds time scale at the soft X-ray synchrotron facilities, where the core-levels of the elements of interest can be probed. For these experiments, a femtosecond laser pump pulse is combined with the $\sim 70$ picosecond soft X-ray probe. Valence band dynamics in the range of the tens of femtoseconds on the other hand will be addressed by using ultra- and extreme ultra-violet light pulses obtained by high-harmonic-generation (HHG) in laserbased table-top experiments. Here a $\sim 20$ fs laser pump source will be used to excite the sample, followed by an HHG pulse in the energy range up to $100 \mathrm{eV}$ to probe the change in the valence band of the excited systems. The first demonstration of this technique on a micro-jet has been presented by Abel and co-workers. ${ }^{86}$ While the HHG will reveal dynamics of the valence band, the XFEL can probe such dynamics at the corelevel (beyond the water window). Another dimension of induced ultra-fast dynamics has been addressed with our recently proposed DCFY mechanism. Nevertheless, the mechanism is awaiting quantitative studies to reveal its physical and chemical contribution for sensing the bond structure and the induced dynamics through the chemical bond.

\section{Acknowledgements}

This work was supported by the Helmholtz-Gemeinschaft via the young investigator fund VH-NG-635. Part of this work was financially supported by the European Research Council grant No. 279344.

\section{References}

1 L. Pauling, The Nature of the Chemical Bond, Cornell University Press, Ithaca, New York, 1938.

2 P. Wernet, Phys. Chem. Chem. Phys., 2011, 13, 16941-16954.

3 M. Chergui and A. H. Zewail, ChemPhysChem, 2009, 10, $28-43$.

4 E. F. Aziz, M. H. Rittmann-Frank, K. M. Lange, S. Bonhommeau and M. Chergui, Nat. Chem., 2010, 2, 853-857.

5 M. Bauer, T. Stalinski and E. F. Aziz, ChemPhysChem, 2011, 12, 2088-2091.
6 D. F. Ogletree, H. Bluhm, E. D. Hebenstreit and M. Salmeron, Nucl. Instrum. Methods Phys. Res., Sect. A, 2009, 601, 151-160.

7 K. Nishizawa, N. Kurahashi, K. Sekiguchi, T. Mizuno, Y. Ogi, T. Horio, M. Oura, N. Kosugi and T. Suzuki, Phys. Chem. Chem. Phys., 2011, 13, 413-417.

8 R. Seidel, S. Thürmer, J. Moens, P. Geerlings, J. Blumberger and B. Winter, J. Phys. Chem. B, 2011, 115, 11671-11677.

9 S. A. Priola, A. Raines and W. S. Caughey, Science, 2000, 287, $1503-1506$.

10 W. S. Caughey, S. A. Priola, L. D. Raymond, M. Horiuchi, A. E. Raines and B. Caughey, Abstr. Pap. Am. Chem. Soc., 1999, 217, U1138-U1138.

11 R. Hudson, M. Carcenac, K. Smith, L. Madden, O. J. Clarke, A. Pelegrin, J. Greenman and R. W. Boyle, Br. J. Cancer, 2005, 92, $1442-1449$.

12 A. K. Burrell, D. L. Officer, P. G. Plieger and D. C. W. Reid, Chem. Rev., 2001, 101, 2751-2796.

13 H. Wende, M. Bernien, J. Luo, C. Sorg, N. Ponpandian, J. Kurde, J. Miguel, M. Piantek, X. Xu, P. Eckhold, W. Kuch, K. Baberschke, P. M. Panchmatia, B. Sanyal, P. M. Oppeneer and O. Eriksson, Nat. Mat., 2007, 6, 516-520.

14 J. R. Stromberg, A. Marton, H. L. Kee, C. Kirmaier, J. R. Diers, C. Muthiah, M. Taniguchi, J. S. Lindsey, D. F. Bocian, G. J. Meyer and D. Holten, J. Phys. Chem. C, 2007, 111, 15464-15478.

15 A. L. Smeigh, M. Creelman, R. A. Mathies and J. K. McCusker, J. Am. Chem. Soc., 2008, 130, 14105.

16 V. A. Montes, C. Perez-Bolivar, L. A. Estrada, J. Shinar and P. Anzenbacher, J. Am. Chem. Soc., 2007, 129, 12598.

17 L. X. Chen, X. Y. Zhang, E. C. Wasinger, K. Attenkofer, G. Jennings, A. Z. Muresan and J. S. Lindsey, J. Am. Chem. Soc., 2007, 129, 9616.

18 L. X. Chen, W. J. H. Jager, G. Jennings, D. J. Gosztola, A. Munkholm and J. P. Hessler, Science, 2001, 292, 262-264.

19 L. X. Chen, X. Y. Zhang, E. C. Wasinger, J. V. Lockard, A. B. Stickrath, M. W. Mara, K. Attenkofer, G. Jennings, G. Smolentsev and A. Soldatov, Chem. Sci., 2010, 1, 642-650.

20 H. E. Song, M. Taniguchi, J. R. Diers, C. Kirmaier, D. F. Bocian, J. S. Lindsey and D. Holten, J. Phys. Chem. B, 2009, 113, 16483-16493.

21 C. Kirmaier, H. E. Song, E. Yang, J. K. Schwartz, E. Hindin, J. R. Diers, R. S. Loewe, K. Y. Tomizaki, F. Chevalier, L. Ramos, R. R. Birge, J. S. Lindsey, D. F. Bocian and D. Holten, J. Phys. Chem. B, 2010, 114, 14249-14264.

22 E. F. Aziz, J. Phys. Chem. Lett., 2011, 2, 320-326.

23 J. Grasjo, E. Andersson, J. Forsberg, L. Duda, E. Henke, W. Pokapanich, O. Björneholm, J. Andersson, A. Pietzsch, F. Hennies and J. E. Rubensson, J. Phys. Chem. B, 2009, 113, 16002-16006.

24 E. F. Aziz, J. Electron Spectrosc. Relat. Phenom., 2010, 177, 168.

25 E. F. Aziz, W. Eberhardt and S. Eisebitt, Z. Phys. Chem., 2008, 222, 727-738.

26 N. Ottosson, E. F. Aziz, H. Bergersen, W. Pokapanich, G. Öhrwall, S. Svensson, W. Eberhardt and O. Björneholm, J. Phys. Chem. B, 2008, 112, 16642-16646.

27 E. F. Aziz, S. Eisebitt, F. de Groot, J. Chiou, C. Dong, J. Guo and W. Eberhardt, J. Phys. Chem. B, 2007, 111, 4440-4445.

28 Y. Horikawa, T. Tokushima, Y. Harada, O. Takahashi, A. Chainani, Y. Senba, H. Ohashi, A. Hiraya and S. Shin, Phys. Chem. Chem. Phys., 2009, 11, 8676-8679.

29 N. Bergmann, S. Bonhommeau, K. M. Lange, S. M. Greil, S. Eisebitt, F. de Groot, M. Chergui and E. F. Aziz, Phys. Chem. Chem. Phys., 2010, 12, 4827-4832.

30 E. F. Aziz, S. Eisebitt, W. Eberhardt, L. Cwiklik and P. Jungwirth, J. Phys. Chem. B, 2008, 112, 1262-1266.

31 E. F. Aziz, M. Freiwald, S. Eisebitt and W. Eberhardt, Phys. Rev. B: Condens. Matter, 2006, 73, 75120.

32 N. Ottosson, E. F. Aziz, I. L. Bradeanu, S. Legendre, G. Öhrwall, S. Svensson, O. Björneholm and W. Eberhardt, Chem. Phys. Lett., 2008, 460, 540-542.

33 E. F. Aziz, N. Ottosson, S. Eisebitt, W. Eberhardt, B. JagodaCwiklik, R. Vacha, P. Jungwirth and B. Winter, J. Phys. Chem. B, 2008, 112, 12567-12570.

34 E. F. Aziz, A. Zimina, M. Freiwald, S. Eisebitt and W. Eberhardt, J. Chem. Phys., 2006, 124, 114502. 
35 I. Waluyo, C. C. Huang, D. Nordlund, T. M. Weiss, L. G. M. Pettersson and A. Nilsson, J. Chem. Phys., 2011, 134, 224507.

36 Y. Harada, M. Taguchi, Y. Miyajima, T. Tokushima, Y. Horikawa, A. Chainani, Y. Shiro, Y. Senba, H. Ohashi, H. Fukuyama and S. Shin, J. Phys. Soc. Jpn., 2009, 78, 044802.

37 S. Schreck, G. Gavrila, C. Weniger and P. Wernet, Rev. Sci. Instrum., 2011, 82, 103101.

38 M. Nagasaka, T. Hatsui, T. Horigome, Y. Hamamura and N. Kosugi, J. Electron Spectrosc. Relat. Phenom., 2010, 177, 130-134.

39 E. F. Aziz, N. Ottosson, S. Bonhommeau, N. Bergmann, W. Eberhardt and M. Chergui, Phys. Rev. Lett., 2009, 102, 68103.

40 D. Panzer, C. Beck, M. Hahn, J. Maul, G. Schönhense, H. Decker and E. F. Aziz, J. Phys. Chem. Lett., 2010, 1, 1642-1647.

41 K. M. Lange, U. Bergmann, K. F. Hodeck, R. Konnecke, U. Schade and E. F. Aziz, Phys. Chem. Chem. Phys., 2011, 13, 15423-15427.

42 S. Dixit, J. Crain, W. C. K. Poon, J. L. Finney and A. K. Soper, Nature, 2002, 416, 829-832.

43 J. H. Guo, Y. Luo, A. Augustsson, S. Kashtanov, J. E. Rubensson, D. K. Shuh, H. Agren and J. Nordgren, Phys. Rev. Lett., 2003, 91, 157401.

44 H. K. Kashyap and R. Biswas, J. Chem. Phys., 2007, 127, 184502. 45 Y. Marcus, Chem. Rev., 1988, 88, 1475-1498.

46 B. L. Eggimann and J. I. Siepmann, J. Phys. Chem. C, 2008, 112, 210-218.

47 P. Jungwirth and D. J. Tobias, J. Phys. Chem. B, 2002, 106, 6361-6373.

48 K. M. Lange, K. F. Hodeck, U. Schade and E. F. Aziz, J. Phys. Chem. B, 2010, 114, 16997-17001.

49 M. Faubel, B. Steiner and J. P. Toennies, J. Chem. Phys., 1997, 106, 9013-9031.

50 C. D. Cappa, J. D. Smith, B. M. Messer, R. C. Cohen and R. J. Saykally, J. Phys. Chem. B, 2006, 110, 5301-5309.

51 B. M. Messer, C. D. Cappa, J. D. Smith, K. R. Wilson, M. K. Gilles, R. C. Cohen and R. J. Saykally, J. Phys. Chem. B, $2005, \mathbf{1 0 9}, 5375-5382$.

52 R. J. Saykally, J. S. Uejio, C. P. Schwartz, A. M. Duffin, W. S. Drisdell and R. C. Cohen, Proc. Natl. Acad. Sci. U. S. A., 2008, 105, 6809-6812.

53 E. F. Aziz, N. Ottosson, M. Faubel, I. V. Hertel and B. Winter, Nature, 2008, 455, 89-91.

54 K. M. Lange, R. Könnecke, S. Ghadimi, R. Golnak, M. A. Soldatov, K. F. Hodeck, A. Soldatov and E. F. Aziz, Chem. Phys., 2010, 377, 1-5.

55 K. M. Lange, R. Könnecke, M. A. Soldatov, R. Golnak, J.-E. Rubensson, A. Soldatov and E. F. Aziz, Angew. Chem., Int. Ed., 2011, 123, 10809-10813.

56 T. Tokushima, Y. Harada, Y. Horikawa, O. Takahashi, Y. Senba, H. Ohashi, L. G. M. Pettersson, A. Nilsson and S. Shin, J. Electron Spectrosc. Relat. Phenom., 2010, 177, 192-205.

57 L. Weinhardt, O. Fuchs, M. Blum, M. Bär, M. Weigand, J. D. Denlinger, Y. Zubavichus, M. Zharnikov, M. Grunze, C. Heske and E. Umbach, J. Electron Spectrosc. Relat. Phenom., 2010, 177, 206-211.

58 T. Tokushima, Y. Harada, O. Takahashi, Y. Senba, H. Ohashi, L. G. M. Pettersson, A. Nilsson and S. Shin, Chem. Phys. Lett., 2008, 460, 387-400.

59 L. W. Pinkley, P. P. Sethna and D. Williams, J. Opt. Soc. Am., 1977, 67, 494-499.

60 R. Lemus, M. Carvajal, J. C. Lopez-V and A. Frank, J. Mol. Spectrosc., 2002, 214, 52-68.

61 C. Bressler and M. Chergui, Chem. Rev., 2004, 104, 1781-1812.

62 C. Bressler, C. Milne, V. T. Pham, A. ElNahhas, R. M. van der Veen, W. Gawelda, S. Johnson, P. Beaud, D. Grolimund,
M. Kaiser, C. N. Borca, G. Ingold, R. Abela and M. Chergui, Science, 2009, 323, 489-492.

63 M. Khalil, M. A. Marcus, A. L. Smeigh, J. K. McCusker, H. H. W. Chong and R. W. Schoenlein, J. Phys. Chem. A, 2006, 110, 38-44.

64 B. Ahr, M. Chollet, B. Adams, E. M. Lunny, C. M. Laperle and C. Rose-Petruck, Phys. Chem. Chem. Phys., 2011, 13, 5590-5599.

65 F. A. Lima, C. J. Milne, D. C. V. Amarasinghe, M. H. RittmannFrank, R. M. van der Veen, M. Reinhard, V. T. Pham, S. Karlsson, S. L. Johnson, D. Grolimund, C. Borca, T. Huthwelker, M. Janousch, F. van Mourik, R. Abela and M. Chergui, Rev. Sci. Instrum., 2011, 82, 063111.

66 L. X. Chen, Angew. Chem., Int. Ed., 2004, 43, 2886-2905.

67 N. Huse, H. D. Wen, D. Nordlund, E. Szilagyi, D. Daranciang, T. A. Miller, A. Nilsson, R. W. Schoenlein and A. M. Lindenberg, Phys. Chem. Chem. Phys., 2009, 11, 3951-3957.

68 H. D. Wen, N. Huse, R. W. Schoenlein and A. M. Lindenberg, J. Chem. Phys., 2009, 131, 234505.

69 G. Gavrila, K. Godehusen, C. Weniger, E. T. J. Nibbering, T. Elsaesser, W. Eberhardt and P. Wernet, Appl. Phys. A: Mater. Sci. Process., 2009, 96, 11-18.

70 N. Huse, T. K. Kim, L. Jamula, J. K. McCusker, F. M. F. de Groot and R. W. Schoenlein, J. Am. Chem. Soc., 2010, 132, 6809-6816.

71 N. Huse, H. Cho, K. Hong, L. Jamula, F. M. F. de Groot, T. K. Kim, J. K. McCusker and R. W. Schoenlein, J. Phys. Chem. Lett., 2011, 2, 880-884.

72 B. Winter, Nucl. Instrum. Methods Phys. Res., Sect. A, 2009, 601, 139-150.

73 B. Winter, E. F. Aziz, N. Ottosson, M. Faubel, N. Kosugi and I. V. Hertel, J. Am. Chem. Soc., 2008, 130, 7130-7138.

74 N. Ottosson, R. Vácha, E. F. Aziz, W. Pokapanich, W. Eberhardt, S. Svensson, G. Öhrwall, P. Jungwirth, O. Björneholm and B. Winter, J. Chem. Phys., 2009, 131, 124706.

75 D. Nolting, E. F. Aziz, N. Ottosson, M. Faubel, I. V. Hertel and B. Winter, J. Am. Chem. Soc., 2007, 129, 14068-14073.

76 B. Winter, E. F. Aziz, U. Hergenhahn, M. Faubel and I. V. Hertel, J. Chem. Phys., 2007, 126, 124504.

77 C. Cappa, D. E. Smith, K. R. Wilson and R. J. Saykally, J. Phys.: Condens. Matter, 2008, 20, 205105.

78 A. Charvat, E. Lugovoj, M. Faubel and B. Abel, Rev. Sci. Instrum., 2004, 75, 1209-1218.

79 R. K. Hocking, E. C. Wasinger, F. M. F. de Groot, K. O. Hodgson, B. Hedman and E. I. Solomon, J. Am. Chem. Soc., 2006, 128, 10442-10451.

80 C. C. D. Moulin, F. Villain, A. Bleuzen, M. A. Arrio, P. Sainctavit, C. Lomenech, V. Escax, F. Baudelet, E. Dartyge, J. J. Gallet and M. Verdaguer, J. Am. Chem. Soc., 2000, 122, 6653-6658.

81 M. Ohno and G. A. van Riessen, J. Electron Spectrosc. Relat. Phenom., 2003, 128, 1-31.

82 F. M. F. de Groot, M. A. Arrio, P. Sainctavit, C. Cartier and C. T. Chen, Solid State Commun., 1994, 92, 991-995.

83 S. Eisebitt, T. Bske, J. E. Rubensson and W. Eberhardt, Phys. Rev. B: Condens. Matter, 1993, 47, 14103-14109.

84 R. Seidel, S. Ghadimi, K. M. Lange, S. Bonhommeau, M. Soldatov, R. Golnak, A. Kothe, R. Könnecke, A. Soldatov, S. Thürmer, B. Winter and E. F. Aziz, J. Am. Chem. Soc., 2012, 134, 1600-1605.

85 L. A. Naslund, M. Cavalleri, H. Ogasawara, A. Nilsson, L. G. M. Pettersson, P. Wernet, D. C. Edwards, M. Sandstrom and S. Myneni, J. Phys. Chem. A, 2003, 107, 6869-6876.

86 K. R. Siefermann, Y. X. Liu, E. Lugovoy, O. Link, M. Faubel, U. Buck, B. Winter and B. Abel, Nat. Chem., 2010, 2, 274-279. 